\title{
The prognosis of cyclical vomiting syndrome
}

\author{
F Dignan, D N K Symon, I AbuArafeh, G Russell
}

\begin{abstract}
Aims-The medium term prognosis of cyclical vomiting syndrome (CVS) was studied to determine the proportion of affected individuals who had gone on to develop headaches fulfilling the International Headache Society criteria for migraine.

Methods-Twenty six (76\%) of 34 CVS sufferers identified from the authors' clinical records were traced, and all agreed to participate. Each child was matched to a control, and telephone interviews were conducted using a standardised questionnaire.

Results-Thirteen (50\%) of the subjects had continuing CVS and/or migraine headaches while the remainder were currently asymptomatic. The prevalence of past or present migraine headaches in subjects $(46 \%)$ was significantly higher than in the control population (12\%).

Conclusion-Results support the concept that CVS is closely related to migraine. (Arch Dis Child 2001;84:55-57)
\end{abstract}

Keywords: migraine; cyclical vomiting syndrome; headache

Cyclical vomiting syndrome (CVS), first described by Gee, ${ }^{1}$ is a childhood condition with an estimated prevalence of $1.9 \% .^{2}$ It is characterised by recurrent, sudden, and self limiting episodes of nausea, vomiting, and lethargy during which the child looks pale, ill, and miserable..$^{3-5}$ Each attack lasts from a few hours to a few days, and there is complete resolution of symptoms between attacks.

The aetiology of the condition is uncertain. It has been linked to epilepsy, ${ }^{67}$ psychological problems, ${ }^{8-10}$ metabolic disorders, ${ }^{11}$ and autonomic dysfunction ${ }^{12}$ but in the great majority of children no abnormality is found. Many authors consider that CVS is a "migraine equivalent". ${ }^{13}$ In a previous study, ${ }^{14}$ we found a similar pattern of associated symptoms in children with CVS and those with abdominal migraine, also considered a migraine equivalent. We have also noted relations between CVS and migraine in an epidemiological study; in particular, children with CVS have an excess of migraineurs among their first degree relatives. ${ }^{2}$

Also supportive of a relation to migraine is the response of CVS to antimigraine drugs. It may respond to pizotifen, ${ }^{8}$ a serotonin antagonist, to propanolol, ${ }^{16}$ and to cyproheptadine, ${ }^{17}$ an antihistamine with serotonin antagonist and calcium blocking properties, all of which are used in the prophylaxis of migraine. A positive response has also been noted in a case treated with sumatriptan, ${ }^{18}$ a $5-\mathrm{HT}_{1}$ agonist used in the acute management of migraine.

Further support for a relation between CVS and migraine comes from electrophysiological studies. Quantitative electroencephalogram (EEG) changes in CVS are similar to patterns recorded in migraine. ${ }^{19}$ Good $^{20}$ performed a detailed analysis of visual evoked responses, and identified similarities between CVS and migraine, with or without aura.

Although the links between CVS and migraine are widely (although not universally ${ }^{21}$ ) accepted, it is unclear if children with CVS continue to have attacks of vomiting as they get older, or if the condition transforms into more typical migraine. We have therefore examined the medium term prognosis of CVS to determine the proportion who have gone on to develop headaches that fulfil the International Headache Society ${ }^{22}$ criteria for migraine.

\section{Methods}

ETHICAL APPROVAL

The study was approved by the Joint Ethical Committee of the University of Aberdeen and Grampian Health Board.

POPULATION

Subjects were identified from clinical records maintained by DNKS, IAA, and GR. We identified 34 individuals in whom a diagnosis of CVS had been made, based on previously published criteria $^{2}$ (see table 1). We identified controls, matched for sex and week of birth, by using the hospital birth records; three potential controls were found for each case and were contacted in turn until one responded.

QUESTIONNAIRE BASED TELEPHONE INTERVIEWS An initial letter was sent to the home address of each child, detailing the aims of the study and explaining that they would subsequently be contacted by telephone. At telephone interview, we then enquired about headache and vomiting in the past year. We used a previously validated headache questionnaire ${ }^{23}$; table 2 shows additional questions on cyclical vomit-

\section{Table 1 Criteria for the diagnosis of cyclic vomiting}

At least three episodes in the past year, in an otherwise apparently healthy child, of unexplained nausea and vomiting that were:

- sudden in onse

- self limiting

- accompanied by pallor, lethargy, and misery

- not associated with gastrointestinal or systemic symptoms between attacks

Table 2 Questions relating to cyclic vomiting attacks

Do you suffer from vomiting attacks?

If you are sick, do you also get pain?

Is there anything you feel causes an attack? 
Table 3 The prognosis of cyclic vomiting syndrome

\begin{tabular}{|c|c|c|c|c|c|c|}
\hline & \multicolumn{2}{|l|}{ Total $(n=26)$} & \multicolumn{2}{|c|}{ Boys $(n=11)$} & \multicolumn{2}{|c|}{ Girls $(n=15)$} \\
\hline & $\begin{array}{l}\text { Subjects } \\
n(\% \text { total; } 95 \% C I)\end{array}$ & $\begin{array}{l}\text { Controls } \\
n(\% \text { total; } 95 \% C I)\end{array}$ & $\begin{array}{l}\text { Subjects } \\
n(\%)\end{array}$ & $\begin{array}{l}\text { Controls } \\
n(\%)\end{array}$ & $\begin{array}{l}\text { Subjects } \\
n(\%)\end{array}$ & $\begin{array}{l}\text { Controls } \\
n(\%)\end{array}$ \\
\hline No current CVS & $18(69 ; 48.2$ to 85.7$)$ & $25(96 ; 80.4$ to 99.9$)$ & $10(91)$ & $11(100)$ & $8(53)$ & $14(93)$ \\
\hline No migraine headache at any time & $8(31 ; 14.3$ to 51.8$)$ & $23(88 ; 69.8$ to 97.6$)$ & $4(36)$ & $10(91)$ & $4(27)$ & $13(86.7)$ \\
\hline Current migraine headache & $5(19 ; 6.6$ to 39.3$)$ & $2(8 ; 0.1$ to 25.1$)$ & $3(27)$ & $1(9)$ & $2(13)$ & $1(7)$ \\
\hline Previous migraine headache, now resolved & $5(19 ; 6.6$ to 39.3$)$ & $0(0 ; 0$ to 13.2$)$ & $3(27)$ & $0(0)$ & $2(13)$ & $0(0)$ \\
\hline Current CVS & $8(31 ; 14.3$ to 51.8$)$ & $1(4 ; 0.1$ to 19.6$)$ & $1(9)$ & $0(0)$ & $7(47)$ & $1(7)$ \\
\hline No migraine headache at any time & $6(23 ; 9.0$ to 43.6$)$ & $0(0 ; 0$ to 13.2$)$ & $1(11)$ & $0(0)$ & $5(33)$ & $0(0)$ \\
\hline Current migraine headache & $2(8 ; 0.1$ to 25.1$)$ & $1(4 ; 0.1$ to 19.6$)$ & $0(0)$ & $0(0)$ & $2(13)$ & $1(7)$ \\
\hline Total migraine headache, past or present & $12(46 ; 26.6$ to 66.6$)$ & $3(12 ; 2.5$ to 30.2$)$ & $6(55)$ & $1(9)$ & $6(40)$ & $2(13)$ \\
\hline
\end{tabular}

ing. In addition to questioning the child, one parent, usually the mother, was consulted to confirm the accuracy of the information.

STATISTICAL ANALYSIS

The proportions of symptomatic subjects were compared using the $\chi^{2}$ test.

\section{Results}

TELEPHONE INTERVIEWS

Of the 34 children fulfilling our criteria for CVS, current addresses were available for 26 $(76 \%)$. These comprised 15 females and 11 males, and all agreed to participate in the study. The mean age of respondents was 17 years. There were no significant age or sex differences between those who could and could not be traced.

PROGNOSIS OF CVS

Table 3 presents the results. Of the CVS subjects, eight $(31 \%)$ were still experiencing vomiting attacks. Twelve $(46 \%)$ had a current or previous history of headaches that fulfilled the International Headache Society criteria for migraine, compared to only three $(12 \%)$ of the controls, a difference that was statistically significant (using Fisher's exact test, two tailed, $\mathrm{p}=0.0128)$.

\section{Discussion}

This investigation is the first case control study to follow up a population of children previously diagnosed with CVS. There is no laboratory test to confirm the diagnosis of CVS, but we have found our clinical criteria easy to apply in both clinical $^{24}$ and epidemiological ${ }^{2}$ settings. Although confusion might arise in psychological disorders such as anorexia nervosa and bulimia, in metabolic disorders such as urea cycle disorders, organic acidaemias, and mitochondrial myopathy, encephalopathy with lactic acidosis and stroke (MELAS), raised intracranial pressure, and infections, especially of the urinary tract, there are usually other clues to these disorders.

We chose to approach our patients for telephone rather than personal interview because our hospital service covers a wide geographic area, and clinical interviews in the hospital were unlikely to find favour with families living at a distance. In addition, commitments at school, college, and work make attendance problematical for this age group. The diagnosis of migraine is based on symptoms, and there are no diagnostic clinical or laboratory findings, so that clinical examina- tion will only rarely influence the diagnosis. We experienced no problems in applying the questionnaire by telephone, and found it easy to interview the teenage subjects and to obtain confirmatory details from a parent.

This follow up study of patients with CVS indicates a strong predisposition on the part of sufferers to develop migraine headache. Almost half had experienced typical migraine headaches, $27 \%$ currently and $19 \%$ previously. In contrast, only $12 \%$ of the control population had ever had migraine, a figure similar to that found in larger populations. ${ }^{25}$ In a previous study, ${ }^{12}$ we found that $38 \%$ of children also suffered from migraine headaches at the time they consulted for CVS. The present study suggests that this proportion increases with the passage of time. Generally, the onset of CVS precedes that of migraine headaches ${ }^{26}$ being at the ages of 5.3 and 8.3 years respectively in our local school population. ${ }^{23}$ It may well be that our findings reflect the tendency for migraine to present with abdominal symptoms in early childhood, with some but not all going on to develop migraine headache as they get older.

About one third of our subjects continued to suffer from cyclical vomiting attacks well into their teens, a finding in keeping with previous reports. ${ }^{27} 28$ It is therefore inappropriate to regard CVS as a purely paediatric condition that disappears at puberty or during adolescence. Not only do sufferers tend to develop migraine headaches, but many also continue to have episodic vomiting.

Our results confirm that there is an association between CVS and migraine headaches and that in a significant proportion of children, the condition transforms into typical migraine headache.

1 Gee S. On fitful or recurrent vomiting. St Bartholomezws Hos-

pital Report 1882;18:1-6.
2 Abu-Arafeh I, Russell G. Cyclical vomiting syndrome in children: a population based study. $\mathcal{F}$ Pediatr Gastroenterol Nutr 1995;21:454-8.

3 Wyllie WG, Schlesinger B. The periodic group of disorders in childhood. Br f Child Dis 1933;30:1-20.

4 Hamilton CKJ. Discussion on cyclical vomiting and allied periodic disorders of childhood. Proc R Soc Med 1951; 44(719): 27.

5 Fleisher DR, Matar M. The cyclic vomiting syndrome: a report of 71 cases and literature review. $\mathcal{F}$ Pediatr Gastroenterol Nutr 1993;17:361-9.

6 Mitchell WG, Greenwood RS, Messenheimer JA. Abdominal epilepsy. Cyclic vomiting as the major symptom in simple partial seizures. Arch Neurol 1983;40:251-2.

7 Millichap J, Lombroso C, Lennox W. Cyclic vomiting as a form of epilepsy in children. Pediatrics 1995;15:705-14.

8 Magagna J. Psychophysiologic treatment of cyclical vomiting. F Pediatr Gastroenterol Nutr 1995;21(suppl 1):S31-6.

9 Reinhart JB, Evans SL, McFadden DL. Cyclic vomit in Reinhart JB, Evans SL, McFadden DL. Cyclic vomit in
children: seen through the psychiatrist's eye. Pediatrics children: seen thro

10 Forbes D, Withers G, Silburn S, McKelvey R. Psychological and social characteristics and precipitants of vomiting in 
children with cyclic vomiting syndrome. Dig Dis Sci 1999; 44(suppl 8):19S-22S.

11 Boles RG, Chun N, Senadheera D, Wong L-JC. Cyclic vomiting syndrome and mitochondrial DNA mutations. Lancet 1997;350:1299-300.

12 Rashed H, Abell TL, Familoni BO, Cardoso S. Autonomic function in cyclic vomiting syndrome and classic migraine. Dig Dis Sci 1999;44:74S-78S

$13 \mathrm{Li}$ BU, Murray RD, Heitlinger LA, Robbins JL, Hayes JR. Is cyclic vomiting syndrome related to migraine? $\mathcal{F}$ Pediatr 1999;134:567-72.

14 Symon DNK, Russell G. The relationship between cyclical vomiting syndrome and abdominal migraine. f Pediatr Gastroenterol Nutr 1995;21(suppl 1):S42-43.

15 Salmon MA, Walters DD. Pizotifen in the prophylaxis of cyclical vomiting. Lancet 1985;I:1036-7.

16 Forbes D, Withers G. Prophylactic therapy in cyclic vomiting syndrome. $\mathcal{F}$ Pediatr Gastroenterol Nutr 1995;21(suppl

17 Andersen JM, Sugerman KS, Lockhart JR, Weinberg WA. Effective prophylactic therapy for cyclic vomiting syndrome in children using amitriptyline or cyproheptadine. Pediatrics 1997;100:977-81.

18 Benson JM, Zorn SL, Book LS. Sumatriptan in the treatment of cyclic vomiting. Ann Pharmacother 1995;29:997-9.

19 Jernigan SA, Ware LM. Reversible quantitative EEG changes in a case of cyclic vomiting: evidence for migraine equivalent. Dev Med Child Neurol 1991;33:80-5.
20 Good PA. Neurologic investigations of childhood abdominal migraine: a combined electrophysiologic approach to diagnosis. If Pediatr Gastroenterol Nutr 1995;21(suppl 1):S44-8.

21 Hockaday JM. Is there a place for "abdominal migraine" as a separate entity in the I.H.S. classification? No! Cephalalgia 1992;12:346-8.

22 Headache Classification Committee of the International Headache Society. Classification and diagnostic criteria for headache disorders, cranial neuralgias and facial pain. Cephalalgia 1988;8(suppl 7):19-28.

23 Tom T, Brody M, Valabhi A, Turner L, Molgaard C, Rothrock J. Validation of a new instrument for determining migraine prevalence: the USCD Migraine Questionnaire. Neurology 1994;44:925-8.

24 Symon DNK, Russell G. Abdominal migraine: a childhood syndrome defined. Cephalalgia 1986;6:223-8.

25 Abu-Arafeh I, Russell G. Prevalence of headache and migraine in schoolchildren. BMF 1994;309:765-9.

26 Vahlquist B. Migraine in children. Int Arch Allergy Appl Immunol 1955;7:348.

27 Hammond J. The late sequelae of recurrent vomiting of childhood. Dev Med Child Neurol 1974;16:15-22.

28 Cavazzuti GB, Ferrari P. Le sindromi periodiche infantili e la loro evoluzione a lungo termine. Ped Med Chir 1982;4:593-600.

\section{Helping disaster victims}

A doctor working for the disaster relief programme of the Pan American Health Organisation and the World Health Organisation (Claude de Ville de Goyet. Lancet 2000;356: 762-4) has made some pungent points about response to disasters.

He points to five "myths": that dead bodies are a major health hazard; that immediate outside help is always needed and helpful; that people behave badly after disasters; that the local population is usually too shocked to help itself; and that things soon get back to normal. The reality, he insists, is that dead bodies do not cause epidemics and the belief that they do leads to hasty, unceremonious, and unseemly disposal of the dead. Foreign teams of experts may have a false idea of local needs, they are not always needed urgently, and when they do arrive they should cooperate more with local workers. Most people respond well to catastrophe, and lawlessness and corruption are the exception rather than the rule. Similarly, far from being too shocked, local people are usually enthusiastic and dedicated volunteers. The effects of disaster are long lasting but international interest and attention are short lived and help may dry up. Early donations are often plentiful but may include inappropriate goods when money would be better.

The World Bank recently announced that, in future, $15 \%$ of its emergency relief grants will go towards reducing vulnerability to disasters and Dr de Ville de Goyet commends this approach to others.

ARCHIVIST 